\title{
Effect of Ultrasound Therapy with Cryokinetics versus Ultrasound Therapy with Soft Tissue Massage (Deep Friction Massage) in Acute Supraspinatus Tendinitis - A Comparative Study
}

\author{
Pradeep Krishna Reddy ${ }^{1}$, Jayashree Dey ${ }^{2}$, Yashodhara S Joshi ${ }^{3}$, Santosh Kumar ${ }^{4}$ \\ ${ }^{1}$ Principal, Vemana Institute of Physiotherapy, Bangalore - 560034 \\ ${ }^{2}$ Physiotherapist, Bangalore. \\ ${ }^{3}$ Lecturer, Vemana Institute of Physiotherapy, Bangalore- 560034 \\ ${ }^{4}$ Associate Professor, Department of Orthopaedics, Kempegowda Institute of Medical Sciences, Bangalore.
}

Corresponding Author: Pradeep Krishna Reddy

\begin{abstract}
Background and Objective: In supraspinatus tendinitis there is inflammatory and or degenerative changes of tendon. This study was done to assess the effectiveness of ultrasound and cryokinetics versus ultrasound and soft tissue massage (deep friction massage) in patients with acute supraspinatus tendinitis.

Method: All subjects were clinically diagnosed by orthopaedician and were screened as per the inclusion and exclusion criteria. 60 patients were randomly divided into 2 groups with $n=30$ each group, Group A- received ultrasound therapy and cryokinetics, whereas Group B- received ultrasound therapy and soft tissue massage. The treatment was given 1 session/day, 6 days/week. The total treatment duration was for 2 weeks.

Outcome Measures: Patients were evaluated on day 1, day 7 and day 14. All the patients were assessed for pain and shoulder functional scale by taking VAS and SPADI.

Results: Both the groups showed statistically significant changes in pre and post values. However, Group B showed greater improvement from baseline to week 1 on VAS and SPADI. After analysis group B showed significance with $\mathrm{P}<0.001^{*}$.

Conclusion: Ultrasound therapy with cryokinetics and ultrasound therapy with soft tissue massage both were effective in reducing pain intensity and increasing the shoulder functional scale but ultrasound therapy with soft tissue massage showed superior hand over ultrasound therapy with cryokinetics.
\end{abstract}

Keywords: Acute Supraspinatus Tendinitis, Ultrasound Therapy, Cryokinetics, Soft Tissue Massage, Visual Analogue Scale, Shoulder Pain And Disability Index.

\section{INTRODUCTION}

Tendinitis is the inflammation of the tendon and results from micro-tears that occurs when the musculotendinous unit is acutely overloaded with a tensile force that is too heavy and/or too sudden. It is a degeneration of the tendon's collagen as a reaction to chronic overuse; when overuse is continued without giving the tendon time to heal and rest, such as with repetitive strain injury, tendinosis results. There is a prevalent supposition that tendinosis begins with tendinitis, which then initiates a healing process that changes the collagen and weakens the tendon. ${ }^{[1]}$

Supraspinatus tendinitis can be described as the non-traumatic, inflammatory and or degenerative changes 
of tendon. It is common in athletes involving repetitive overhead activities like bowling, swimming, and javelin throw etc. And even in individuals involving these repetitive overhead activities at their work places. ${ }^{[2]}$ The prevalence of supraspinatus tendonitis among adults under 65 years of the age ranges from $7 \%$ to $27 \%$, whereas it is between $13.2 \%$ and $26 \%$ among individuals over 65 years of the age. Both the genders are equally affected with supraspinatus tendinitis. ${ }^{[3]}$

Supraspinatus tendinitis can be triggered by extrinsic and intrinsic factors. Extrinsic factors are divided into primary and secondary impingement. Increased subacromial loading, overhead activities, or trauma can cause primary impingement. Supraspinatus tendonitis can also occur because of the reduction in the supraspinatus outlet space due to underlying instability of the glenohumeral joint. ${ }^{[4]}$

Neer proposed Supraspinatus tendinitis in 1972 as a clinical entity in which the rotator cuff was pathologically compressed against the anterior structure of coracoacromial arch, anterior third of the acromion, the coracoacromial ligament, acromioclavicular joint. ${ }^{[5]}$

The amount of force deliverable by a cuff muscle is determined by its size, health and condition as well as the position of the joint. The supraspinatus and infraspinatus provide 45 percent of abduction and 90 percent of external rotation strength. The torques produced by the supraspinatus and deltoid muscles is evenly responsible for producing torque about the shoulder joint in the functional planes of motion. ${ }^{[6]}$

\section{Pathogenesis:}

Tendon is composed of densely arranged collagen fibers, elastin, proteoglycans, and lipids. Tendons are relatively hypovascular proximal to the bone insertion, which is the most common site of tendon overuse injury.

Mechanical impingement, either primary or secondary, results in initiation of inflammatory changes. The supraspinatus insertion to the bone is of the direct type. Most fibers enter at right angles to the bone and referred to as deep fibers.

Immobilization has been shown to cause an increase in avulsion fractures due to loss of underlying bone. Also an acute traumatic overloading of the tendon can cause injury to the bone- tendon junction. In 1970 Ranthburn and Macnab demonstrated a zone of relative avascularity within the supraspinatus tendon near its insertion. They proposed this injury was subject to further insult by compression of the humeral head. They also showed that the avascular zone preceded degenerative cuff changes. Repetitive micro trauma has been associated with ossification of the insertion site.

Hirsch and Morgan attributed these phenomena to the disruption of the cartilage within the insertion site. Nirschl has criticized this theory of Neer especially in the athletic patient stating tendinitis is due to eccentric contraction resulting in micro trauma. Cystic changes at the supraspinatus and infraspinatus insertion sites have been associated with cuff disorders. ${ }^{[7]}$

\section{Pathomechanics:}

Supraspinatus is a degenerative or traumatic, with either an acute or chronic onset. This disorder encompasses a spectrum of pathology of tendinosis to partial thickness and full thickness tears to arthropathy. Tendinitis is the accumulation of scarring in the tendon due to cell death without inflammation. The two principle causes cell deaths are intrinsic tendon overload and extrinsic compression.

Intrinsic overload is generally caused by chronic repetitive micro trauma such as seen in manual overhead workers. One off traumatic episodes can cause acute tendon failure.

Extrinsic compression of the supraspinatus tendon can occur as it runs through the coracoacromial arch. Tendinitis also causes thickening of the supraspinatus tendon that can lead to impingement in coracoacromial arch. ${ }^{[3]}$ 


\section{Diagnosis:}

The first is painful arc sign. This is when a person experiences pain upon abduction of the arm between $60^{\circ}$ and $120^{\circ}$. The next step would be to perform the empty can test. The validity of the empty can test has been studied and shown to have sensitivity of $62 \%, 41 \%$ and $88 \%$ for supraspinatus tendinitis, full thickness tear, and large to massive tears. ${ }^{[8]}$

\section{Symptoms:}

- Sudden onset of sharp pain in the shoulder with tearing sensation.

- Gradual increase in shoulder pain with overhead activities.

- Pain usually around lateral, superior, anterior shoulder occasionally referring to deltoid region.

- Weakness also may found with tendinitis due to muscle inhibition from the pain stimulus.

- Pain with humerus in forward flexed and internally rotated position.

- Pain with humerus abducted and externally rotated position.

Many physiotherapy treatments are in use for or in the treatment of supraspinatus tendinitis some of them are, hot or cold pack application, ultrasound therapy, iontophoresis, deep friction massage, low level laser therapy, short wave diathermy.

The purpose of the treatment is to manage pain and resolve mechanical problems so that the function is improved. The goal of the conservative treatment is to alleviate pain and improve function through reduction of the swelling. ${ }^{[3]}$

Ultrasound refers to mechanical vibrations, which are essentially the same as sound waves but of a higher frequency. Ultrasound induced heating is result of the absorption of ultrasonic energy biological tissues. The objective is to warm tendons, muscle, and other tissues to improve blood flow and accelerate healing. The coupling medium can also include various compounds for enhancing the treatment. ${ }^{[9]}$
Cryokinetics is a systemic combination of cold application to numb the injured body part and graded progressive, active exercises.

Cryotherapy is thought to decrease edema formation via induced vasoconstriction. Reduce secondary hypoxic damage by lowering the metabolic demand of the injured tissue. Cooling skin surface temperature to approximately $15^{0} \mathrm{C}$ from the normal body temperature is also thought to exert a localized analgesic effect by inhibiting the nerve conduction velocity. Thus, facilitating earlier and more aggressive therapeutic exercise after muscle injury.

Exercises increases blood flow to the injured area vital in healing. Exercise reestablishes neuromuscular function. With this technique exercise is possible much earlier than normal. Swelling is reduced dramatically through the combination of cooling and exercises. If the exercise during cryokinetics becomes so vigorous that further damage may result, the body responds with a pain sensation. Thus cryokinetics has a built in safety value. It allows rehabilitation to begin much sooner than traditional thermotherapy and can reduce rehabilitation time by days or even weeks. ${ }^{[10]}$

Deep friction or soft tissue massage is a technique that attempts to reduce abnormal fibrous adhesions and make scar tissue more mobile in acute, sub acute and chronic inflammatory conditions by realigning the normal soft tissue fibers. This technique is principally designated to affect connective tissue of tendon, ligaments, and muscles. ${ }^{\text {[11] }}$

It produces local vasodilatation and also mobilizes the structures in the area. It is an effective means for treating conditions like sprains, strains, tendinitis etc. According to Cyriax, deep transverse friction causes traumatic hyperemia, which results in increased blood flow and decrease in pain. It also increases tissue perfusion and stimulates mechanoreceptors, stimulates circulation, which overcomes the congestion 
within the tendon, reduces/ prevents adhesion formation. ${ }^{[12]}$

The main objectives of the study were:

- To find out the effect of therapeutic ultrasound along with cryokinetics in patients with acute supraspinatus tendinitis.

- To find out the effect of therapeutic ultrasound along with soft tissue massage (deep friction massage) in patients with acute supraspinatus tendinitis.

- To compare the effectiveness of therapeutic ultrasound and cryokinetics over therapeutic ultrasound and soft tissue massage (deep friction massage) in reducing pain and improving shoulder function in patients with acute supraspinatus tendinitis.

\section{MATERIAL AND METHODS}

The study was a hospital centerbased comparative follow up conducted at the outpatient and inpatient department of orthopedics and physiotherapy in Kempegowda Institute of Medical Sciences, Bangalore.

The sample size was 60 (30 subjects in each group).

The following was the inclusion criteria:

- Clinically diagnosed as acute supraspinatus tendinitis.

- Age group 30-60 years

- Males and Females.

- Empty Can Test positive

And the exclusion criteria were as follows:

- Cold urticaria

- Cold intolerance or hypersensitivity

- Deep open wounds in shoulder

- Peripheral Vascular Disease

- Skin areas of impaired somatosensory discrimination

- Ischemic regions around shoulder

- Shoulder Fractures

- Cardiac pacemakers

- Cardiac Condition
- Shoulder dislocation

- Ligament injury in shoulder

- Subjects with clinical disorders like infective conditions of the shoulder, tumor, and metal implant.

- Adhesive Capsulitis

Group A patients were treated with ultrasound and cryokinetics and Group B patients were treated with ultrasound and soft tissue massage.

Before the start of the treatment, the procedure was explained to the patients and the consent form was signed.

Ultrasound being common for both the groups, the patient was prepared accordingly. The applicator is moved in small concentric circular movements. The transducer head was applied to the therapy region at right angle to ensure maximum absorption. Pulsed Ultrasound with a ratio of 1:4 was given over the anterolateral tip of the shoulder with an intensity of $1 \mathrm{w} / \mathrm{cm}^{2}$ and $1 \mathrm{MHz}$ frequency for 5 minutes for a period of 2 weeks at the rate of 1 sitting per day and 6 times a week.

\section{Cryokinetics:}

For Group A, an insulating layer was used between the cold pack and patient's skin.

The subject was in supine position. Cryo pack was applied around the involved shoulder covering superior to posterior, superior to anterior aspects. Treatment was given for 20 minutes following which active exercises were given for 5-7 minutes. Again cryo pack was applied for 5 minutes, then another set of active exercises were given. Exercises included active flexion, extension and abduction of the involved shoulder for ten repetitions. 1 minute of rest session was given and this treatment was given for 6 sessions per week.

\section{Soft Tissue Massage (Deep Friction Massage):}

For Group B, the patients were made to flex his/ her elbow to $90^{\circ}$ and put the forearm behind his/ her back, then lean back in half lying position. Thus arm was fixed in 
adduction and medial rotation. Deep friction massage was given to the supraspinatus tendon with the tip of index finger, which was reinforced by middle finger. It was given in the transverse direction for 10- 12 minutes.

Baseline measurements of pain intensity and shoulder function were assessed using VAS and SPADI, again pre treatment measurements were taken on day 7 , day 14. The patients were requested to come back for follow up measurements after 1 week of the end of treatment program.

\section{Statistical Analysis:}

Descriptive and inferential statistical analysis was carried out in the present study. Results on continuous measurements were presented on Mean \pm SD (Min-Max) and results on categorical measurements were presented in Number (\%). Significance was assessed at $5 \%$ level of significance. The following assumptions on data were made, Assumptions: 1. Dependent variables should be normally distributed. 2 . Samples drawn from the population should be random. 3 . Cases of the samples should be independent.

Student $t$ test (two tailed, independent) was used to find the significance of study parameters on continuous scale between two inter group analysis on metric parameters. Student $t$ test (two tailed, dependent) was used to find the significance of study parameters on continuous scale within each group. And, Chi-square/ Fisher Exact test was used to find the significance of study parameters on categorical scale between two or more groups.

The Statistical software namely SAS 9.2, SPSS 15.0, Stata 10.1, MedCalc 9.0.1, Systat 12.0 and R environment ver.2.11.1 were used for the analysis of the data.

\section{RESULTS}

In the present study, the mean age of group A was 47.53 (SD: 7.59) and the mean age of group B was 46.67 (SD: 8.17). The samples were age matched with $\mathrm{P}=0.672$ and hence age was not a confounding variable.

The age group of study samples ranging from 31-40 years was $20 \%$ in-group $\mathrm{A}$ and $22 \%$ in group B. The age group of study samples ranging from 41-50 years was $50 \%$ in-group A and $48 \%$ in-group B. And that of 51-60years was 35\% in-group A and group B. Therefore it shows that the mean age group of study samples ranged from 30 60 years.

Group A had $53.3 \%$ of females and $46.7 \%$ of male, whereas group B consisted of $53.3 \%$ of males and $46.7 \%$ of females.

Table 1: Comparative evaluation of VAS scores in Group A and Group B.

\begin{tabular}{|l|l|l|l|l|l|l|l|l|l|}
\hline VAS & Baseline & Day 7 & \multirow{2}{*}{ Day 14 } & \multicolumn{2}{|c|}{ Difference } & \multicolumn{3}{|c|}{ Significance } \\
\cline { 5 - 10 } & & & & Baseline & Baseline & Day 7- & Baseline & Baseline & Day 7- \\
\hline Group A & $7.23 \pm 0.6$ & $5.73 \pm 0.8$ & $4.33 \pm 0.9$ & 1.500 & 2.900 & 1.400 & $<0.001^{*}$ & $<0.001^{*}$ & $<0.001^{*}$ \\
\hline Group B & $7.17 \pm 0.7$ & $5.17 \pm 0.9$ & $3.13 \pm 0.8$ & 2.000 & 4.033 & 2.033 & $<0.001^{*}$ & $<0.001^{*}$ & $<0.001^{*}$ \\
\hline P value & 0.709 & $0.015^{*}$ & $<0.001^{*}$ & - & - & - & - & - & - \\
\hline
\end{tabular}

Table 1 represents: Day 1 assessment of VAS score, which was 7.23 (SD: 0.6) in group A while it was 7.17 (SD: 0.7) in group B. VAS score at day 7 assessment was 5.73 (SD: 0.8) in group A and 5.17 (SD: 0.9) in group B. VAS score at day 14 assessment was 4.33 (SD:0.9) in group A and 3.13 (SD: 0.8) in group B. Therefore VAS was significantly reduced in group $\mathrm{B}$ with $\mathrm{P}<0.001^{* *}$.

Table 2: Comparative Evaluation of SPADI in Group A and Group B.

\begin{tabular}{|c|c|c|c|c|c|c|c|c|c|}
\hline \multirow[b]{2}{*}{ SPADI } & \multirow[b]{2}{*}{ Baseline } & \multirow[b]{2}{*}{ Day 7} & \multirow[b]{2}{*}{ Day 14} & \multicolumn{3}{|c|}{ Difference } & \multicolumn{3}{|c|}{ Significance } \\
\hline & & & & $\begin{array}{l}\text { Baseline- } \\
\text { day } 7\end{array}$ & $\begin{array}{l}\text { Baseline- } \\
\text { day } 14\end{array}$ & $\begin{array}{l}\text { Day 7- } \\
\text { day14 }\end{array}$ & $\begin{array}{l}\text { Baseline- } \\
\text { day } 7\end{array}$ & $\begin{array}{l}\text { Baseline- } \\
\text { day } 14\end{array}$ & $\begin{array}{l}\text { Day 7- } \\
\text { day14 }\end{array}$ \\
\hline Group A & $109.90 \pm 7.14$ & $100.97 \pm 6.51$ & $96.53 \pm 6.30$ & 5.933 & 10.367 & 4.433 & $<0.001 * *$ & $<0.001 * *$ & $<0.001 * *$ \\
\hline Group B & $106.67 \pm 5.81$ & $75.37 \pm 6.56$ & $55.73 \pm 6.38$ & 34.300 & 53.933 & 19.633 & $<0.001 * *$ & $<0.001 * *$ & $<0.001 * *$ \\
\hline $\mathrm{P}$ value & 0.105 & $<0.001 * *$ & $<0.001 * *$ & - & - & - & - & - & - \\
\hline
\end{tabular}


Table 2 represents: Day 1 assessment of SPADI score, which was 109.90 (SD: 7.14) in group A, while it was 106.67 (SD: 5.81) in group B. SPADI score at day 7 assessment was 100.97 (SD: 6.51) in group A and 75.37 (SD: 6.56) in group B. SPADI score at day 14 assessment was 96.53 (SD: 6.30) in group A and 55.73 (SD: 6.38) in group B. Therefore SPADI is significantly reduced in group $B$ with $\mathrm{P}<0.001^{* *}$.

\section{DISCUSSION}

The present study was conducted to study the effectiveness of ultrasound therapy and cryokinetics in comparison with ultrasound therapy and soft tissue massage.

According to a study, De Berardino $\mathrm{T}$ concluded that supraspinatus tendinitis was reported to be more common in people whose job requires repetitive overhead motion and athletes who complete in sports such as swimming, throwing sports, volleyball.

In this study ultrasound therapy and soft tissue massage showed beneficial results in the treatment of acute supraspinatus tendinitis. So group B has shown more improvement than group A that is proved statistically.

Between the patients interviewed, both males and females in both groups are almost equally affected with acute supraspinatus tendinitis. With $46.7 \%$ of males in-group $\mathrm{A}$ and $53.3 \%$ in-group B, and $53.3 \%$ of females in-group $\mathrm{A}$ and $46.7 \%$ in-group B.

In relation to age, this study shows that the incidence of patients with acute supraspinatus is more in the age group of 30- 60 years. Percentage distribution with regards to age in-group $\mathrm{A}$ is $20 \%$ at the age of $31-40$ years, $50 \%$ at the age group of 41 50 years, and 35\% at the age of 51-60 years. In-group B, it is $22 \%$ at the age group of $31-40$ years, $48 \%$ at the age group of $41-50$ years and 35\% at the age group of 51-60 years. According to Andre Roy (2010), shoulder pathologies increases as age increases.
In the present study, ultrasound therapy and soft issue massage was found to be better than ultrasound therapy and cryokinetics.

This result supports the findings by Nauslund (2001) who claimed that ultrasound was effective in seven randomized controlled trial in the review of medicine literature and few other studies. [13]

The effectiveness of ultrasound depends upon the intensity, frequency, and duration of treatment. The dose of ultrasound chosen in this study was from the evidence available in the literature. Pulsed ultrasound was used. It is preferred for soft tissue repair with the pulsed ratio 1:4 as per Dyson M. The high intensity can be potentially damaging so the dose of $1 \mathrm{w} / \mathrm{cm}^{2}$ was used. ${ }^{[14]}$

According to the results of deep friction massage technique; we can state that it is highly effective in treating supraspinatus tendinitis. These findings support the study done by Guler UF et al (2004) and Gimblett PA et al (1999) who stated that deep friction massage is an effective means of treating soft tissue lesions. But these results were contraindicating to the findings of Brosseau et al (2002) who stated that soft tissue massage is not effective for controlling pain in tendinitis because it showed no significant improvement in VAS score.

The technique used in this study had evidence from the literature. Positioning of patients arm behind the back was used in this study as it bends the supraspinatus tendon through the right angle passing from base of coracoid process directly forward over the head of humerus. Massage was given with tip of index finger, as it is an effective method.

These results of the study also got strong evidences from the study done by Shamshi Sharick (2013) who has done a comparative study of effectiveness of ultrasound and massage alone in treatment of acute supraspinatus tendinitis. The result of the study suggests that ultrasound and 
deep friction massage improves the pain symptoms of supraspinatus tendinitis. Deep friction massage alone improved the pain symptoms but was too small to reach. ${ }^{[15]}$ This study implies that both ultrasound therapy with cryokinetics and ultrasound therapy with soft tissue massage (deep friction massage) can be used for treating patient with acute supraspinatus tendinitis.

\section{Limitations of the study:}

1. The study was limited to the age group of 30-60 years.

2. The study was limited to acute supraspinatus tendinitis.

3. The study was limited to assess only the pain intensity by using VAS and shoulder functional scale by using SPADI.

4. The study was of a short duration with a follow up period of only 1 week.

\section{Suggestions and further recommendation:}

1. As this study was done only with acute supraspinatus tendinitis, further studies are also suggested to detect the progress in patients with other soft tissue conditions like sprain, strain etc.

2. Further studies should be conducted with a larger sample size and with a wider age.

3. A long duration study should be conducted with longer follow up sessions to know the effectiveness of treatment.

\section{CONCLUSION}

The study concluded by taking mean scores that therapeutic ultrasound with cryokinetics and therapeutic ultrasound with soft tissue massage are both efficient and useful in rehabilitation of patient with acute supraspinatus tendinitis. They improved the functional ability, relieved pain and considerably improved the physical performance of patients in their own aspects.

However, therapeutic ultrasound with soft tissue massage (group B) showed significant improvement than therapeutic ultrasound with cryokinetics (group A) in reducing pain and enhancing functional performance in patients with acute supraspinatus tendinitis.

\section{Acknowledgement: None}

Conflict of Interest: None

\section{Source of Funding: None}

\section{Ethical Approval: Approved}

\section{REFERENCES}

1. Pankaj Sharma, Nikola Maffuli. Tendon Injury and Tendinopathy: Healing and Repair. The Journal Of Bone And Joint Surgery. Am. 87:187-202, 2005.

2. Rene Calliet. Shoulder Pain. $3^{\text {rd }}$ Edition. Jaypee Brothers: New Delhi.1992; 54- 62.

3. Pia Nyman, Kaj Palenius, Harri Panula, EskoMalkia, Clas-Hakan Nygard. Clinical Study Improvement in Functional Ability and Quality of Life Takes Place among Patients with Supraspinatus Tendinitis Regardless of the Type of Intervention. International Scholarly Research Network ISRN Rehabilitation. 2011;10.

4. Gamze Senbursa, Gul Baltaci, O. Ahmet Atay. The Effectiveness of Manual Therapy in Supraspinatus Tendinopathy. Acta Orthop. Traumatol Turc. 2011; 45(3): 162167.

5. Pose Sgarlat Myers. Saunders Manual Physical Therapy Practice. $1^{\text {st }}$ Edition. Philadelphia, Jitendra P Vij, 2001; Page no. 798.

6. Jacobson Do, Edward C, Michael D, Lockwood DO, Kuchera DO. Shoulder Pain \& Repetition Strain Injury to the Supraspinatus muscle, Etiology \& Manupulative Treatment. Journal of the American Osteopathic association.89 (1989): 1037- 1040.

7. Wing K. Chang. Shoulder Impingement Syndrome. Phys. Med. Rehabil. Clin. N. Am. 15 (2004): 493-510.

8. Holtby MB, Richard, Helen Razmjou. Validity of the Supraspinatus Test in Diagnosing Patients with Rotator Cuff Pathology. Journal of Orthop. \& Sports Physical Therapy. 34(2004): 194-200. 
Pradeep Krishnareddy et.al. Effect of ultrasound therapy with cryokinetics versus ultrasound therapy with soft tissue massage (deep friction massage) in acute supraspinatus tendinitis - a comparative study.

9. Douglas L. Miller, Nadine B. Smith, Michael R. Bailey. Overview of Therapeutic Ultrasound Application \& Safety Considerations. Journal of Ultrasound Medicine. 2012; 31: 623-634.

10. Chad Starkey. Therapeutic Modalities, $4^{\text {th }}$ Edition. F.A Davis, 2013; Page no. 123129.

11. Lucie Brosseau, Lyn Casimiro, Sarah Milne et al. Deep transverse friction massage for treating tendinitis. The Cochrane Library 2009, Issue 1.

12. Cyriax J. Theory and Practice of Massage. Textbook of Orthopaedics Medicine, Treatment by Manipulation, Massage and Injection. Vol.2:11 ${ }^{\text {th }}$ edition. Balilliere Tindall: London. 1984.

13. Naslund J. Mode of Sensory Stimulation: Clinical trials and Physiological aspects. Physiotherapy. 2001; 87(8): 413-423.
14. Dyson M, Preston R, Woledge $\mathrm{R}$ and kitchen S. Long Wave Ultrasound. Physiotherapy.1999; 85(1): 40-49.

15. Shamshi Sharick, Khan Shabana, Abdel Kader Samiha. A Comparative Study of Effectiveness of Ultrasound \& Massage Combined and Massage Alone in Treatment of supraspinatus Tendinitis. Indian Journal Of Physiotherapy and Occupational Therapy - An International Journal. 2013, Vol.6, Issue 4: 96-100.

How to cite this article: Reddy PK, Dey J, Joshi YS et.al. Effect of ultrasound therapy with cryokinetics versus ultrasound therapy with soft tissue massage (deep friction massage) in acute supraspinatus tendinitis - a comparative study. Int J Health Sci Res. 2021; 11(7): 249-256. DOI: https://doi.org/10.52403/ijhsr.20210734 